\title{
Relation Between Medium-Range Order and Crystallization in Al-Ni Based Metallic Glass
}

\author{
S.H. Wang*, W. Wang and Q.D. Wang
}

Hebei University of Engineering, Handan, 056038, China

\begin{abstract}
The structure evolutions of $\mathrm{Al}_{83} \mathrm{Ni}_{10} \mathrm{Ce}_{5} \mathrm{Si}_{2}, \mathrm{Al}_{83} \mathrm{Ni}_{10} \mathrm{Ce}_{7}, \mathrm{Al}_{85} \mathrm{Ni}_{10} \mathrm{Ce}_{5}, \mathrm{Al}_{87} \mathrm{Ni}_{7} \mathrm{Nd}_{6}$ and $\mathrm{Al}_{87} \mathrm{Ni}_{5} \mathrm{Co}_{2} \mathrm{Nd}_{6}$ metallic glasses have been studied in detail. The studies establish a relation between the amount of medium range order (MRO) and crystallization mode. An increased amount of MRO suppresses the precipitation of primary fcc-Al and transforms the crystallization mode from a primary crystallization $\left(\mathrm{Al}_{87} \mathrm{Ni}_{7} \mathrm{Nd}_{6}\right)$ to a eutectic crystallization $\left(\mathrm{Al}_{87} \mathrm{Ni}_{5} \mathrm{Co}_{2} \mathrm{Nd}_{6}\right)$; while a decreasing amount of MRO promotes the precipitation of primary fcc- $\mathrm{Al}$ and transforms the crystallization mode from a eutectic crystallization $\left(\mathrm{Al}_{83} \mathrm{Ni}_{10} \mathrm{Ce}_{7}\right.$ and $\left.\mathrm{Al}_{85} \mathrm{Ni}_{10} \mathrm{Ce}_{5}\right)$ to a primary crystallization $\left(\mathrm{Al}_{83} \mathrm{Ni}_{10} \mathrm{Ce}_{5} \mathrm{Si}_{2}\right)$.
\end{abstract}

Keywords: Metallic glasses, differential scanning calorimetry (DSC), crystallization.

\section{INTRODUCTION}

Al-rich metallic glasses, containing transition metal (TM) and rare earth (RE) elements have attracted considerable attentions due to the occurrence of primary crystallization reaction that yields a microstructure with $\mathrm{Al}$ nanocrystals dispersion embedded in an amorphous matrix to deserve excellent mechanical properties [1-7]. Primary crystallization behavior is empirically related to Al-rich composition $(\geq 87$ at. \% Al) [8-10]. To understand the origin of crystallization, various competing models have been proposed, such as heterogeneous nucleation [11], the presence of a large density of quenched-in nuclei in the amorphous $[2,12]$, a new kind of homogeneous nucleation mechanism ('linked flux') $[13,14]$ and a phase separation mechanism which indicates nucleation of fcc-Al arises at the interface of the phase separation regions [15]. However, the correct crystallization mechanism has yet to be identified in the Albased metallic glasses.

The characteristic of the MRO remains one of the most important questions in metallic glass research $[16,17]$. The MRO can be defined as the next-level structural organization beyond the SRO [18]. The existence of MRO is usually characterized by the presence of prepeak in the structure factor $(S(Q))$ which has gradually been employed as one research tool for metallic glass. Recently, the MRO has been found to play an important role in the primary crystallization of Zr-based metallic glasses [19, 20].

In this report, we propose the amount of MRO as a new criterion to evaluate the crystallization. The different addition can promote or suppress the formation of MRO, and eventually, to influence the crystallization mode.

*Address correspondence to this author at the Hebei University of Engineering, Handan, 056038, China;

Tel: +86-310-8579535; Fax: +86-310-8579556;

E-mail: shenghaiw@163.com

\section{EXPERIMENTAL PROCEDURES}

Al-Ni based ingots were prepared by arc melting nominal amount of high purity elements in a purified argon atmosphere. Amorphous ribbons of thickness about $30 \mathrm{um}$ and width about $2 \mathrm{~mm}$ were prepared by a single roller melting-spinning apparatus. The precipitated phases at different temperatures were assessed by X-ray diffraction (D/max-rB) using $\mathrm{Cu} \mathrm{K}_{\alpha}$ radiation. The thermal properties were characterized by using a differential scanning calriometry (Netzsch DSC 404).

The experimental results have proved the pre-peaks in the liquid's total structure factor are influenced by the temperature [22]. In order to cancel the influence of temperature on the pre-peak of liquid alloys, we reheated all the ingots up to approximately $50 \mathrm{~K}$ above the liquidus temperature and then quenched them into the amorphous state. The cooling rate can also influence the prepeak, so the quenched rate is set to be a constant circumferential speed of $33 \mathrm{~m} / \mathrm{s}$.

The method for obtaining the total structure factor $S(Q)$ can be found in many works [21-23, 28]. There are two main equations for calculating $S(Q)$ :

$. S(Q)=I_{e u}^{c o h} /\left\langle f^{2}(Q)\right\rangle$.

$\cdot\left\langle f^{2}(Q)\right\rangle=\sum_{i} c_{i} f_{i}^{2}(Q)$

where $Q=4 \pi \sin \theta / \lambda$ is the magnitude of the scattering vector, $\lambda$ is the wavelength, $I_{e u}^{c o h}$ is the coherent scattering intensity per atom in electron units, $c_{i}=N_{i} / N, N_{i}$ is the number of type- $i$ atoms and $f_{i}(Q)$ is the type- $i$ atomic scattering factor.

\section{EXPERIMENTAL RESULTS}

Fig. (1) shows DSC curves of $\mathrm{Al}_{83} \mathrm{Ni}_{10} \mathrm{Ce}_{7}$, $\mathrm{Al}_{83} \mathrm{Ni}_{10} \mathrm{Ce}_{5} \mathrm{Si}_{2}$ and $\mathrm{Al}_{85} \mathrm{Ni}_{10} \mathrm{Ce}_{5}$ melt-spun. Clearly, $\mathrm{Al}_{83} \mathrm{Ni}_{10} \mathrm{Ce}_{7}$ and $\mathrm{Al}_{85} \mathrm{Ni}_{10} \mathrm{Ce}_{5}$ metallic glasses, corroborated 
in ref. [10, 24], are both of typical eutectic crystallization, with fcc-Al and compound precipitated in the first stage crystallization. Three exothermic peaks are observed in the $\mathrm{Al}_{83} \mathrm{Ni}_{10} \mathrm{Ce}_{5} \mathrm{Si}_{2}$ metallic glass.

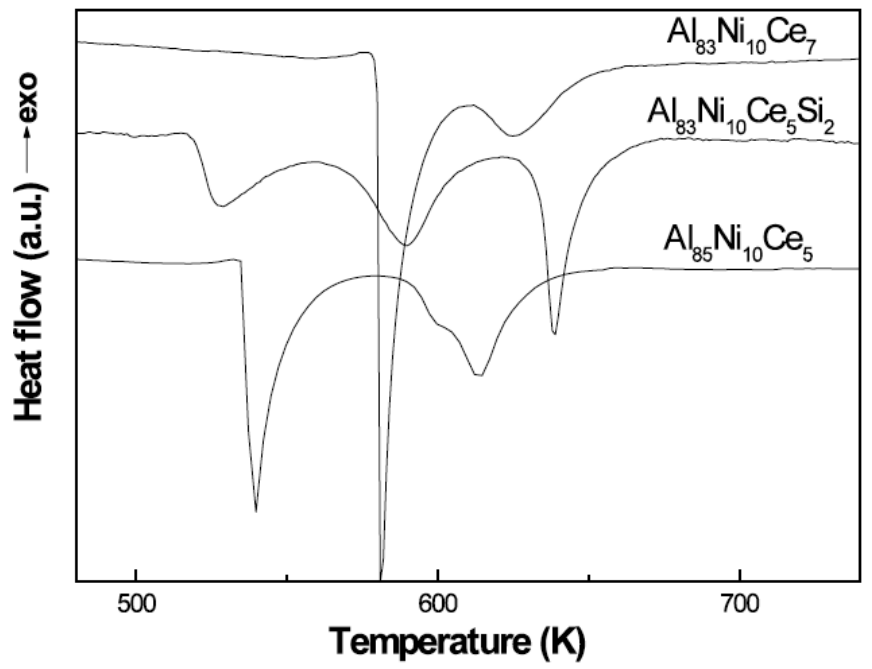

Fig. (1). DSC curves of $\mathrm{Al}_{83} \mathrm{Ni}_{10} \mathrm{Ce}_{7}, \mathrm{Al}_{83} \mathrm{Ni}_{10} \mathrm{Ce}_{5} \mathrm{Si}_{2}$ and $\mathrm{Al}_{85} \mathrm{Ni}_{10} \mathrm{Ce}_{5}$ metallic glasses at a heating rate of $10 \mathrm{~K} / \mathrm{min}$.

To verify the origin of exothermic peaks in the DSC curve of $\mathrm{Al}_{83} \mathrm{Ni}_{10} \mathrm{Ce}_{5} \mathrm{Si}_{2}$ metallic glass, XRD experiments were performed at three different temperatures: first temperature was heated (at a rate of $10 \mathrm{~K} / \mathrm{min}$ ) to $543 \mathrm{~K}$ (first peak) and then to the temperature of $603 \mathrm{~K}$ (second peak), and last one to $720 \mathrm{~K}$ (completed the third peak). Fig. (2) shows the XRD patterns of ribbons continuously heated to above temperatures. Formation of the fcc-Al was observed in the first stage crystallization. The second crystallization reaction is due to precipitations of $\mathrm{Al}_{3} \mathrm{Ni}$ and intermediate metastable phase. Then, the metastable phase gradually decomposed and $\mathrm{Al}_{4} \mathrm{Ce}$ phase formed upon the third peak. After completion of all phase transformation, the final structure consisted of fcc- Al, $\mathrm{Al}_{3} \mathrm{Ni}, \mathrm{Al}_{4} \mathrm{Ce}$ and some unknown phase.

The continuous heating DSC curves of the $\mathrm{Al}_{87} \mathrm{Ni}_{7} \mathrm{Nd}_{6}$ and $\mathrm{Al}_{87} \mathrm{Ni}_{5} \mathrm{Co}_{2} \mathrm{Nd}_{6}$ melt spun are shown in Fig. (3). Three exothermic peaks are seen for $\mathrm{Al}_{87} \mathrm{Ni}_{7} \mathrm{Nd}_{6}$ metallic glass, while two exothermic peaks are seen for $\mathrm{Al}_{87} \mathrm{Ni}_{5} \mathrm{Co}_{2} \mathrm{Nd}_{6}$ metallic glass. Fig. $(\mathbf{4 a}, \mathbf{b})$ shows the XRD pattern of the $\mathrm{Al}_{87} \mathrm{Ni}_{7} \mathrm{Nd}_{6}$ and $\mathrm{Al}_{87} \mathrm{Ni}_{5} \mathrm{Co}_{2} \mathrm{Nd}_{6}$ metallic glasses annealing at 465 (the first exothermic peak) and $512 \mathrm{~K}$ (the first exothermic peak) for $5 \mathrm{~min}$, respectively. Five phases precipitated in the first stage crystallization of $\mathrm{Al}_{87} \mathrm{Ni}_{5} \mathrm{Co}_{2} \mathrm{Nd}_{6}$ metallic glass, including fcc-Al, Al-Nd-Ni, $\mathrm{Al}_{9} \mathrm{Co}_{2}, \mathrm{Al}_{3} \mathrm{Ni}$ and a metastable phase, while only fcc- $\mathrm{Al}$ precipitated in the first stage for $\mathrm{Al}_{87} \mathrm{Ni}_{7} \mathrm{Nd}_{6}$ metallic glass. This indicates that $\mathrm{Al}_{87} \mathrm{Ni}_{7} \mathrm{Nd}_{6}$ and $\mathrm{Al}_{87} \mathrm{Ni}_{5} \mathrm{Co}_{2} \mathrm{Nd}_{6}$ metallic glasses are characteristic of primary crystallization and eutectic crystallization, respectively.

The XRD diffraction patterns of as-quenched samples and the corresponding total structure factors are shown in Figs. (5, 6). Structure factor curves with $Q$ greater than 0.5 $\AA^{-1}$ can be divided into two parts. The first section lies between $0.5-2 \AA^{-1}$ and reflects MRO properties. When there is MRO existing, the curve shows a pre-peak. The second section lying between 2-6 $\AA^{-1}$ includes the first peak that characterizes short-range order (SRO) information. Here, we list the values of $Q_{1}, S\left(Q_{1}\right)$ and crystallization temperature of those experimental metallic glasses in Table $\mathbf{1}$, where $Q_{l}$ represents the position of the prepeak. It can be seen that the prepeak position $Q_{1}$ keeps almost constant for each group, which indicated that the structural unit size corresponding to prepeak keeps unchanged, while the intensity of the prepeak $\left(S\left(Q_{1}\right)\right)$ changes with different compositions.

Fig. (7) shows the total structure factors proposed as a function of the crystallization temperature. The results indicate that the crystallization mode has a relation to the intensity of prepeak.

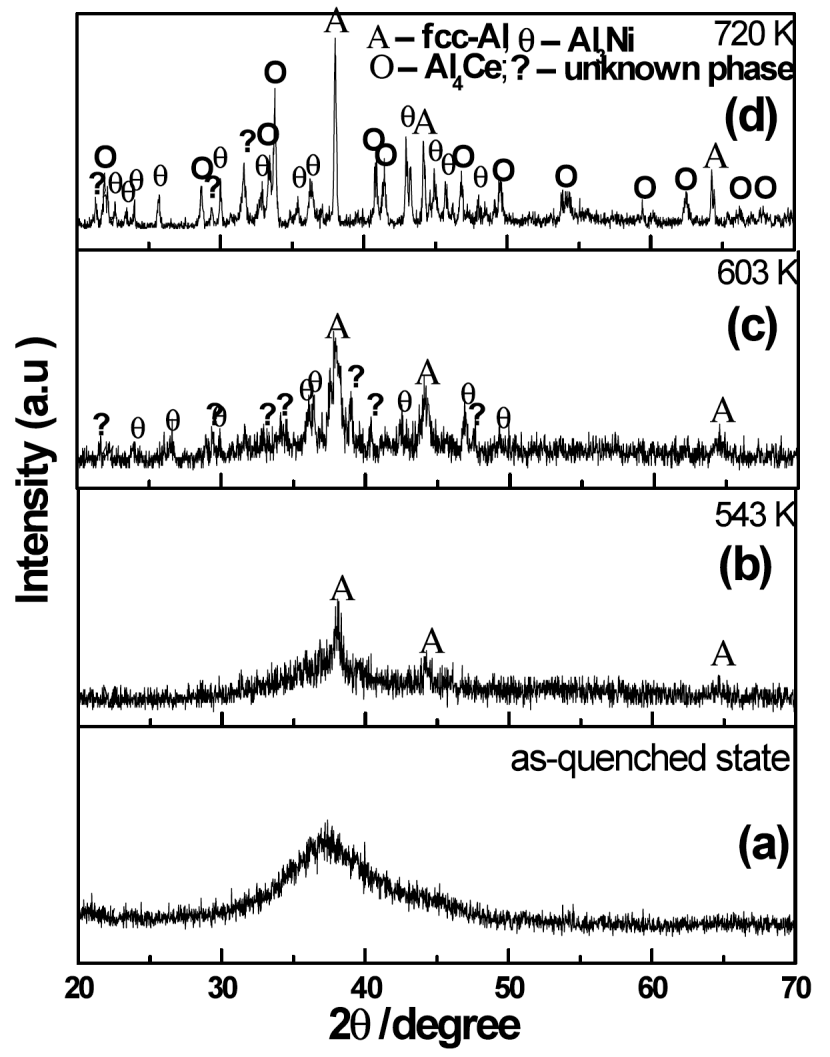

Fig. (2). X-ray diffraction patterns of the $\mathrm{Al}_{83} \mathrm{Ni}_{10} \mathrm{Ce}_{5} \mathrm{Si}_{2}$ metallic glass heating up different temperatures: (a) as-quenched, (b) $543 \mathrm{~K}$, (c) $603 \mathrm{~K}$ and (d) $720 \mathrm{~K}$. (b), (c) and (d) corresponds to the first, second, third exothermic peak in the DSC curve, respectively.

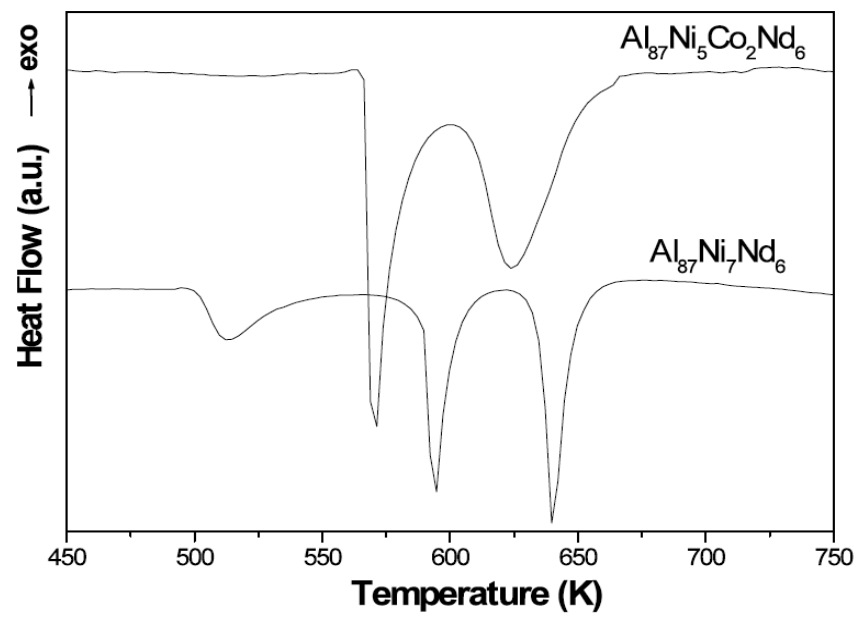

Fig. (3). DSC curves of $\mathrm{Al}_{87} \mathrm{Ni}_{7} \mathrm{Nd}_{6}$ and $\mathrm{Al}_{87} \mathrm{Ni}_{5} \mathrm{Co}_{2} \mathrm{Nd}_{6}$ metallic glasses at a heating rate of $10 \mathrm{~K} / \mathrm{min}$. 


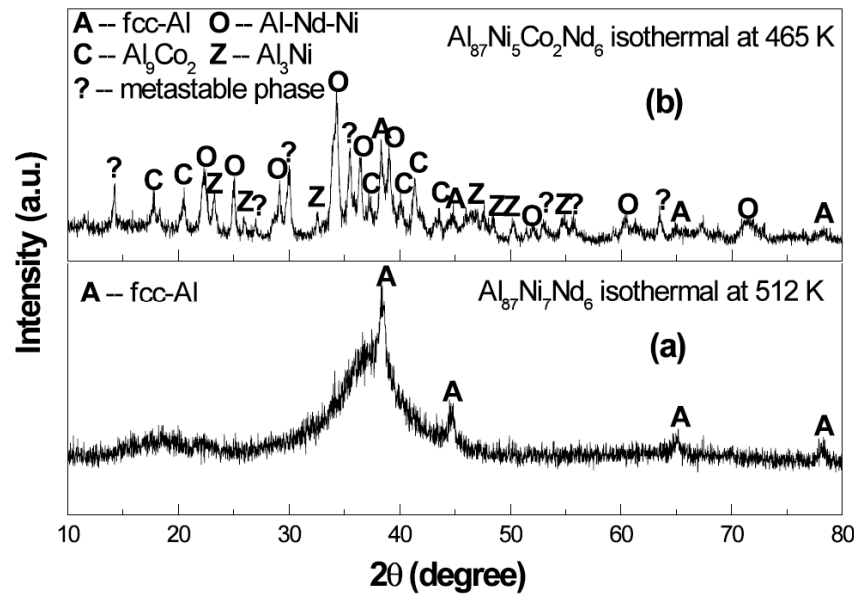

Fig. (4). $\mathrm{X}$-ray diffraction patterns of the $\mathrm{Al}_{87} \mathrm{Ni}_{7} \mathrm{Nd}_{6}$ (a) and $\mathrm{Al}_{87} \mathrm{Ni}_{5} \mathrm{Co}_{2} \mathrm{Nd}_{6}$ (b) metallic glasses annealing at 465 (the first exothermic peak) and $512 \mathrm{~K}$ (the first exothermic peak) for $5 \mathrm{~min}$, respectively.

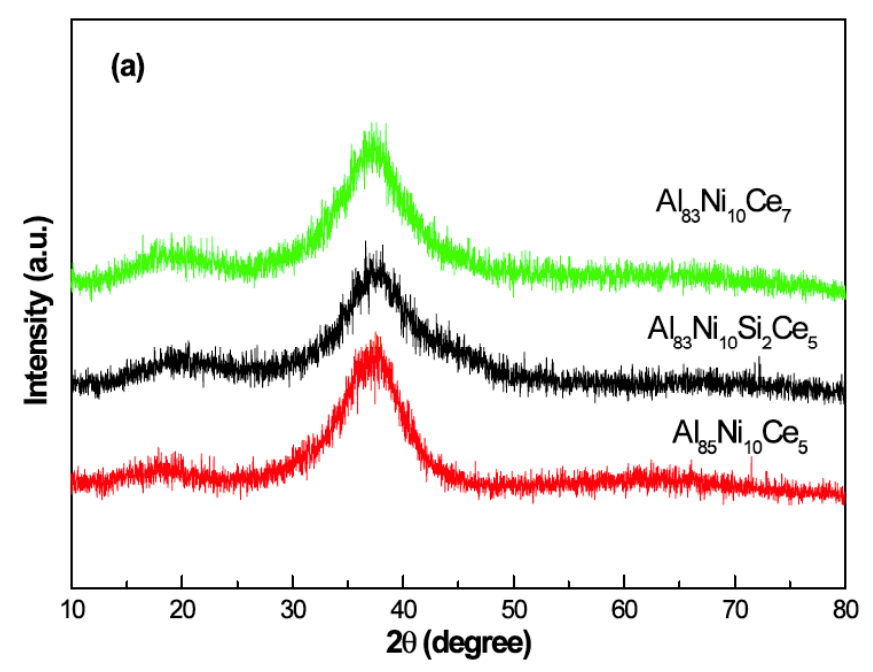

\section{DISCUSSION}

In general, the presence of a prepeak corresponds to compound-forming behaviour [24], or can be attributed to cluster structure constituted of unlike atoms [25]. Zhang et al. [22] have proposed that structural unit corresponding to the prepeak is a medium-range $(0.5-2.0 \mathrm{~nm})$ icosahedral quasicrystalline structure with $\mathrm{Fe}$ as the centred atom in the Al-Fe-Ce metallic glass. As shown in Figs. $(5,6)$, the prepeaks have been found in the total structure factor of all presented samples. Here, in the present alloys, it is suggested that the structure of prepeak may be corresponding to icosahedral MRO, and the prepeak intensity of total structure factor is proportional to the amount of icosahedral MRO.

Primary crystallization of Al-based metallic glasses is usually related to the high $\mathrm{Al}$ concentration [10]. As illustrated in Fig. (1), $\mathrm{Al}_{85} \mathrm{Ni}_{10} \mathrm{Ce}_{5}$ and $\mathrm{Al}_{83} \mathrm{Ni}_{10} \mathrm{Ce}_{7}$ metallic glasses are both typical of eutectic crystallization. While either the $\mathrm{Al}$ or the $\mathrm{Ce}$ was replaced by the $\mathrm{Si}$ for the two alloys, the obtained $\mathrm{Al}_{83} \mathrm{Ni}_{10} \mathrm{Ce}_{5} \mathrm{Si}_{2}$ metallic glass exhibits a unique primary crystallization. Therefore, the occurrence of

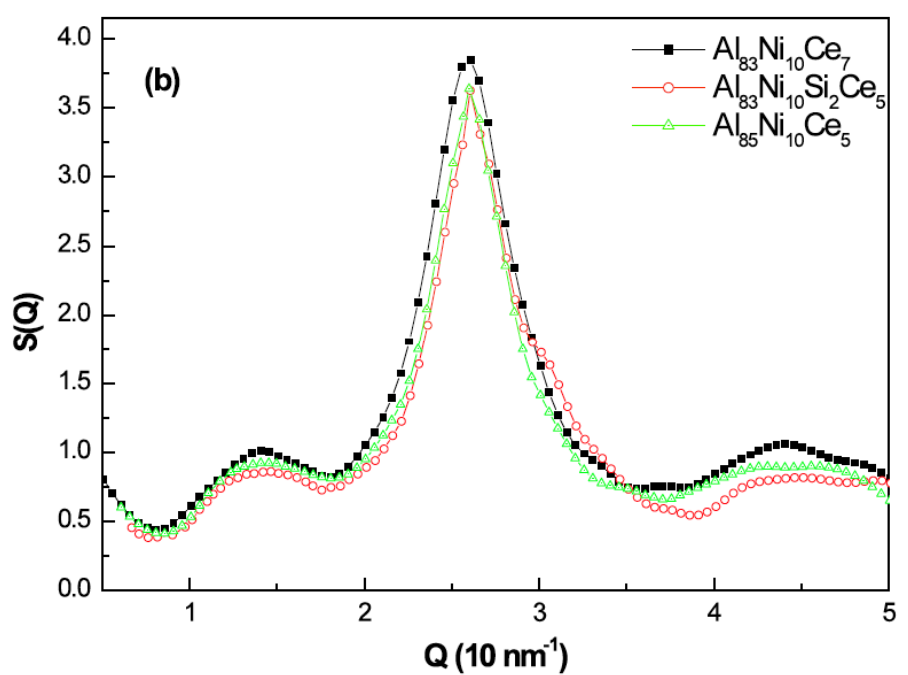

Fig. (5). XRD diffraction patterns (a) of the as-quenched $\mathrm{Al}_{83} \mathrm{Ni}_{10} \mathrm{Ce}_{7}, \mathrm{Al}_{83} \mathrm{Ni}_{10} \mathrm{Ce}_{5} \mathrm{Si}_{2}$ and $\mathrm{Al}_{85} \mathrm{Ni}_{10} \mathrm{Ce}_{5}$ ribbons, and the corresponding total structure factors $(\mathbf{b})$.
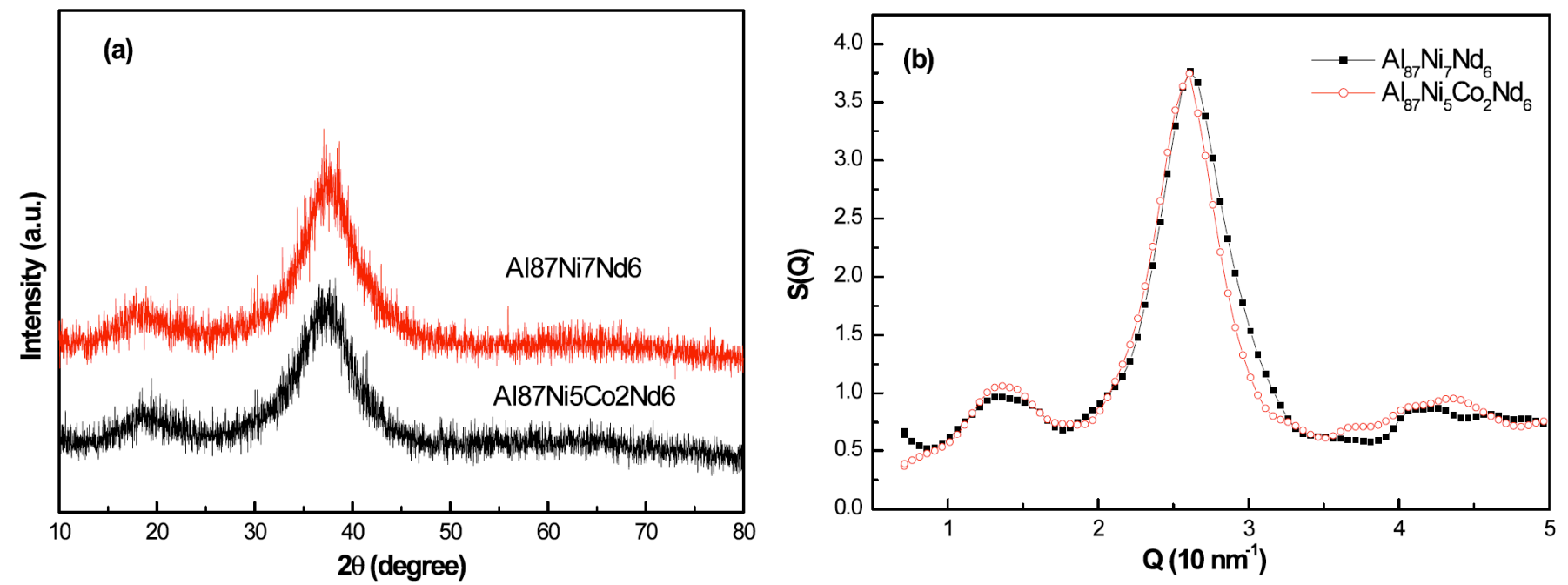

Fig. (6). XRD diffraction patterns (a) of the as-quenched $\mathrm{Al}_{87} \mathrm{Ni}_{7} \mathrm{Nd}_{6}$ and $\mathrm{Al}_{87} \mathrm{Ni}_{5} \mathrm{Co}_{2} \mathrm{Nd}_{6}$ ribbons, and the corresponding total structure factors $(\mathbf{b})$. 

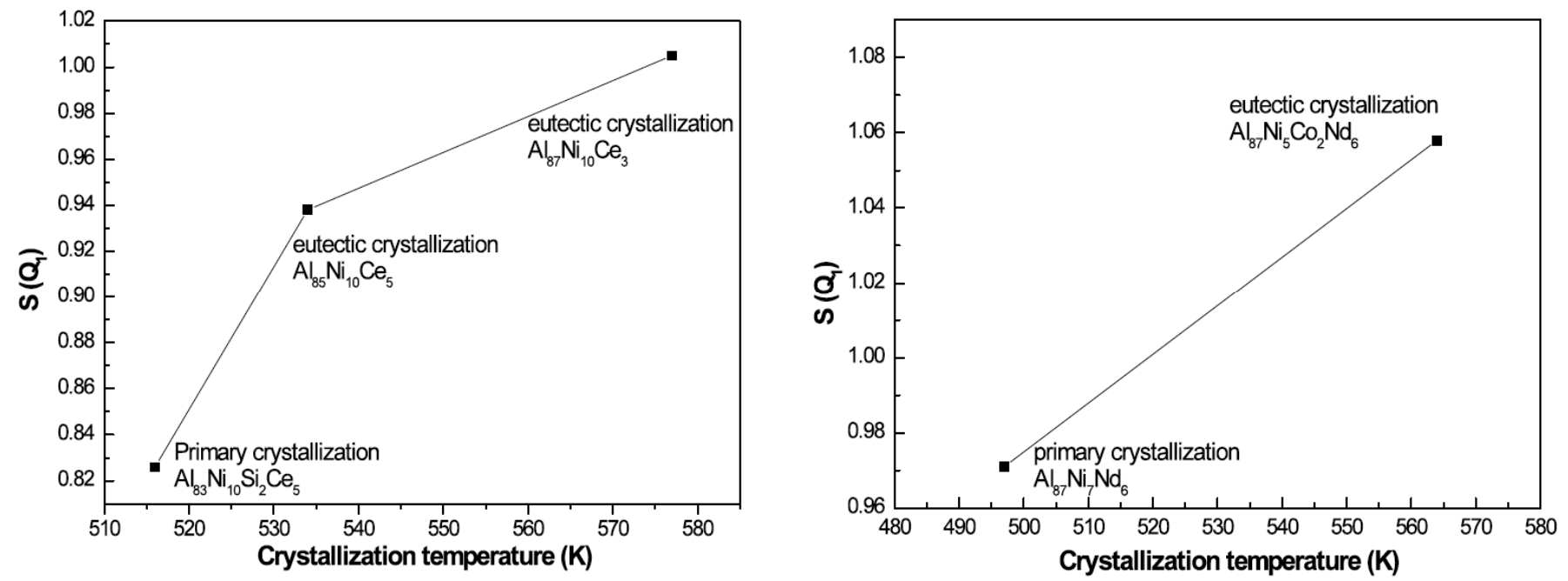

Fig. (7). Correlation between the intensity of the prepeak $S\left(Q_{1}\right)$ and the crystallization temperature.

primary crystallization is not aroused by the high $\mathrm{Al}$ concentration for $\mathrm{Al}_{83} \mathrm{Ni}_{10} \mathrm{Si}_{2} \mathrm{Ce}_{5}$ metallic glass. In the case of $\mathrm{Al}_{83} \mathrm{Ni}_{10} \mathrm{Ce}_{7}, \mathrm{Al}_{85} \mathrm{Ni}_{10} \mathrm{Ce}_{5}$ and $\mathrm{Al}_{83} \mathrm{Ni}_{10} \mathrm{Ce}_{5} \mathrm{Si}_{2}$ metallic glasses, it can be found that the amount of MRO decrease with $\mathrm{Si}$ addition, correspondingly, the crystallization mode transforms from eutectic crystallization $\left(\mathrm{Al}_{83} \mathrm{Ni}_{10} \mathrm{Ce}_{7}\right.$ and $\left.\mathrm{Al}_{85} \mathrm{Ni}_{10} \mathrm{Ce}_{5}\right)$ to primary crystallization $\left(\mathrm{Al}_{83} \mathrm{Ni}_{10} \mathrm{Ce}_{5} \mathrm{Si}_{2}\right)$. A same trend is obtained in the case of $\mathrm{Al}_{87} \mathrm{Ni}_{7} \mathrm{Nd}_{6}$ and $\mathrm{Al}_{87} \mathrm{Ni}_{5} \mathrm{Co}_{2} \mathrm{Nd}_{6}$ metallic glasses. The amount of MRO increase with the Co addition, correspondingly, the crystallization mode transforms from primary crystallization $\left(\mathrm{Al}_{87} \mathrm{Ni}_{7} \mathrm{Nd}_{6}\right)$ to eutectic crystallization $\left(\mathrm{Al}_{87} \mathrm{Ni}_{5} \mathrm{Co}_{2} \mathrm{Nd}_{6}\right)$. This can be well summarized in Fig. (7), which indicates that the amount of MRO has an important effect on the crystallization, that is, an increased amount of MRO can suppress the precipitation of primary fcc-Al, while a decreasing amount of MRO can promote the precipitation of primary fcc-A1. Tanaka [26] has suggested that local icosahedral structures act as random fields against the crystallization during crystallization of intermetallic crystals. Here, it is reasonable to conclude that the increased amount of MRO can keep the amorphous structure more stable and suppress the precipitation of primary fcc-Al.

The present results can be also explained in view of atomic diffusion. It is generally known that the crystallization is accompanied by atomic diffusion to nucleate and grow. Recently, Das [27] found that the alloys liquids with larger prepeak on the total structure factor have smaller diffusion coefficients through using both simulation and the neutron scatting method. This research fruit can well explain the relation between the amount of MRO and crystallization mode, since the amorphous structure can be regarded as the frozen alloy liquid. The decreasing amount of MRO offers a faster diffusion rate to promote the precipitation of primary fcc-Al. While the increased amount of MRO offer a slower diffusion rate to suppress the precipitation of primary fcc-Al.

\section{CONCLUSIONS}

In our present work, the crystallization of $\mathrm{Al}_{85} \mathrm{Ni}_{10} \mathrm{Ce}_{5}$, $\mathrm{Al}_{83} \mathrm{Ni}_{10} \mathrm{Ce}_{7}, \mathrm{Al}_{83} \mathrm{Ni}_{10} \mathrm{Ce}_{5} \mathrm{Si}_{2}, \mathrm{Al}_{87} \mathrm{Ni}_{7} \mathrm{Nd}_{6}$ and $\mathrm{Al}_{87} \mathrm{Ni}_{5} \mathrm{Co}_{2} \mathrm{Nd}_{6}$ metallic glasses have been intensively studied. It is found that the amount of MRO has an important effect on the crystallization behavior. An increased amount of MRO can suppress the precipitation of primary fcc-Al, while a decreasing amount of MRO can promote the precipitation of primary fcc-Al. In the case of $\mathrm{Al}_{85} \mathrm{Ni}_{10} \mathrm{Ce}_{5}, \mathrm{Al}_{83} \mathrm{Ni}_{10} \mathrm{Ce}_{7}$ and $\mathrm{Al}_{83} \mathrm{Ni}_{10} \mathrm{Ce}_{5} \mathrm{Si}_{2}$ metallic glasses, the formation of MRO are suppressed by the $\mathrm{Si}$ addition, and correspondingly, the crystallization mode transforms from a eutectic crystallization $\left(\mathrm{Al}_{85} \mathrm{Ni}_{10} \mathrm{Ce}_{5} / \mathrm{Al}_{83} \mathrm{Ni}_{10} \mathrm{Ce}_{7}\right)$ to a primary crystallization $\left(\mathrm{Al}_{83} \mathrm{Ni}_{10} \mathrm{Ce}_{5} \mathrm{Si}_{2}\right)$. While in the case of $\mathrm{Al}_{87} \mathrm{Ni}_{7} \mathrm{Nd}_{6}$ and $\mathrm{Al}_{87}$ $\mathrm{Ni}_{5} \mathrm{Co}_{2} \mathrm{Nd}_{6}$ metallic glasses, a primary crystallization $\left(\mathrm{Al}_{87}\right.$ $\left.\mathrm{Ni}_{7} \mathrm{Nd}_{6}\right)$ transforms into a eutectic crystallization $\left(\mathrm{Al}_{87} \mathrm{Ni}_{5}\right.$ $\mathrm{Co}_{2} \mathrm{Nd}_{6}$ ), as a consequence of the Co addition which increases the amount of MRO.

Table 1. Values of the Prepeak Position $Q_{1}$ and the Corresponding Intensity $S\left(Q_{1}\right)$ in the Metallic Glasses

\begin{tabular}{|c|c|c|c|}
\hline & $\boldsymbol{Q}_{\boldsymbol{l}}$ & $\boldsymbol{S}\left(\boldsymbol{Q}_{\boldsymbol{l}}\right)$ & Crystallization Temperature (K) \\
\hline \hline $\mathrm{Al}_{83} \mathrm{Ni}_{10} \mathrm{Ce}_{7}$ & 1.408 & 1.005 & 577 \\
\hline $\mathrm{Al}_{83} \mathrm{Ni}_{10} \mathrm{Ce}_{5} \mathrm{Si}_{2}$ & 1.408 & 0.826 & 516 \\
\hline $\mathrm{Al}_{85} \mathrm{Ni}_{10} \mathrm{Ce}_{5}$ & 1.412 & 0.938 & 534 \\
\hline $\mathrm{Al}_{87} \mathrm{Ni}_{5} \mathrm{Co}_{2} \mathrm{Nd}_{6}$ & 1.341 & 1.058 & 564 \\
\hline $\mathrm{Al}_{87} \mathrm{Ni}_{7} \mathrm{Nd}_{6}$ & 1.346 & 0.971 & 497 \\
\hline
\end{tabular}

\section{ACKNOWLEDGEMENT}

This work has been supported by the Science Foundation of Hebei (project Number. 09395113D).

\section{REFERENCE}

[1] Wu RI, Wilde G, Perepezko JH. Glass formation and primary nanocrystallization in Al-base metallic glasses. Mater Sci Eng A 2001; 301: 12-17.

[2] Allen DR, Foley JC, Perepezko JH. Nanocrystal development during primary crystallization of amorphous alloys. Acta Mater 1998; 46: 431-40.

[3] Foley JC, Allen DR, Perepezko JH. Strategies for the development of nanocrystalline materials through devitrification. Mater Sci Eng A $1997 ;$ 226-228: 569-73. 
[4] Chen H, He Y, Shiflet GJ. Mechanical properties of partially crystallized aluminum based metallic glasses. Scr Metall Mater 1991; 25: 1421-24.

[5] Tian N, Ohnuma M, Hono K. Heating rate dependence of glass transition and mary crystallization of $\mathrm{Al} \mathrm{Gd} \mathrm{Er} \mathrm{Ni} \mathrm{metallic} \mathrm{glass.}$ Scr Mater 2005; 53: 681-85.

[6] Sahoo KL, Wollgarten M, Haug MJ, J. Effect of La on the crystallization behaviour ofamorphous A194 xNi6Lax ( $\mathrm{x}=4-7)$ alloys. Acta Mater 2005; 53: 3861-70.

[7] Inoue A. Amorphous, nanoquasicrystalline and nanocrystalline alloys in Al-based systems. Prog Mater Sci 1998; 43: 365-520.

[8] Guo FQ, Poon SJ, Shiflet GJ, Investigation of glass formability in Al-based multinary alloys. Scripta mater 2000; 43: 1089-95.

[9] Gao MC, Shiflet GJ. Devitrification sequence map in the glass forming Al-Ni-Gd system. Scr Mater 2005; 53: 1129-34.

[10] Tsai AP, Kamiyama T, Kawamura Y. Formation and precipitation mechanism of nanoscale Al particles in Al-Ni base amorphous alloys. Acta Mater 1997; 45: 1477-87.

[11] Calin M, Koster U. Nanocrystallization of Al-Ni-Y and Al-Ni-Nd Metallic Glasses. Mater Sci Forum 1998; 269: 749-54.

[12] Foley JC, Allen DR, Perepezko JH. Analysis of nanocrystal development in Al-Y-Fe and Al-Sm glasses. Scr Mater 1996; 35: 655-60.

[13] Kelton KF. Time-dependent nucleation in partitioning transformations. Acta Mater 2000; 48: 1967-80.

[14] Kelton KF. Liquid structure and long range diffusion: their impact on glass formation and nanoscale devitrification. Intermetallics 2006; 14: 966-71.

[15] Gangopadhay AK, Croat TK. The effect of phase separation on subsequent crystallization in A188Gd6La2Ni4. Acta Mater 2000; 48: $4035-43$.

[16] Gaskell PH, Medium-range structure in glasses and low-Q structure in neutron and X-ray scattering data. J Non-Cryst Solids 2005; 351: 1003-13.
[17] Bian XF, Sun BA, Hu LN. Medium-Range Order Structure and Fragility of Superheated Melts of Amorphous CuHf Alloys. Chin Phys Lett 2006; 23: 1864-67.

[18] Gu TK, Qin JY, Bian XF. Correlation between local structure of melts and glass forming ability for Al-based alloys: A firstprinciples study. Appl Phys Lett 2007: 91: 596-601.

[19] Fan C, Louzguine DV, Chunfei L. Nanocrystalline composites with high strength obtained in $\mathrm{Zr}$-Ti-Ni-Cu-Al bulk amorphous alloys. Appl Phys Lett 1999; 75: 340-33.

[20] Saida JJ, Matsushita M, Inoue A. Direct observation of icosahedral cluster in Zr70Pd30 binary glassy alloy. Appl Phys Lett 2001; 79: 412-14.

[21] Qin JY, Gu TK, Tian XL. Study of the structure of molten Fe-Si alloys. J Phys Condens Matter 2004; 16: 4753-460.

[22] Wang L, Cong HR, Bian XF. Medium-range order structure in Al80Fe20 alloy during rapid solidification. Phys Lett A 2002; 301: 477-83.

[23] Li Hui, Bian XF. Structural studies of clusters in melt of FeAl compound. J Chem Phys 2001; 114: 6413-16.

[24] $\mathrm{Hu}$ LN, Bian, XF Wang, WM Wang. Liquid fragility and characteristic of the structure corresponding to the prepeak of AlNiCe amorphous alloys. Acta Mater 2004; 52: 4773-81.

[25] Hoyer W, Jodicke R. Short-range and medium-range order in liquid Au---Ge alloys. J Non-Cryst Solids 1995; 191-192: 102-5.

[26] Tanaka H. Roles of local icosahedral chemical ordering in glass and quasicrystal formation in metallic glass formers. J Phys: Condens Matter 2003; 15: L491-98

[27] Das SK, Horbach J, Koza MM. Influence of chemical short-range order on atomic diffusion in Al-Ni melts. Appl Phys Lett 2005; 86: 011918-19.

[28] Zhang B, Bian XF, Fu CX. An important factor powerfully influencing the Al-Ni-based alloys' glass-forming ability. J Phys: Condens Matter 2005; 50: 7885-93. 